\title{
An Investigation on the Major Problems Encountered in Translating English into Wolaita Language: Two Selected Primary Schools in Focus
}

\author{
Mesfin Mekuria Dangore \\ Department of English Language and Literature, Wolaita Sodo University, Ethiopia \\ P.O. Box: 138
}

\begin{abstract}
s
The main aim of this study was to investigate the major problems encountered in translating English into Wolaita language on students' learning of English at the two selected primary schools. For selecting students, simple random sampling technique was employed. Concerning the sample size, top-three (first 3 ranking) students were selected to be interviewed from the two schools having 11 sections, 6 from Hobicha Borkoshe and 5 sections from Hobicha Bada primary school. In this way, 33 sample students were selected from the two schools to be interviewed. The predominant instrument employed for data collection from the sample respondents was recording; as a result, three different English teachers' classroom lessons were audio-taped having one BA holder from Hobicha Borkoshe primary school and two diploma holders from Hobicha Bada primary school. Moreover, lessons were audio-taped so as to get rich data on the translation activities conducted in the classroom and to get the data that may appear difficult to get through other tools. Another major purpose of this instrument was to analyze the lessons presented and translated in connection to the major criticisms forwarded against the use of translation and students' L1 in English classroom. Even though the researcher introduced teachers that observation and recordings were for the research purpose only, the exact objectives of this study were not disclosed. This was intended to prevent the problem of sensitizing teachers and students to show behavior different from the usual ones and by the help of this technique to get more natural data. To analyze the responses given through each tool, descriptive survey method was employed. Results of the data show that both teachers and students have positive attitudes toward the use of translation except a few who reject it. The study also showed that teachers use translation in English classroom. Even if audio-taped lessons indicated some mismatch of translated sentences and the original English language versions, the majority of sample students further agreed that translation and L1 use helps them to make difficult concepts easy; to feel comfort; to feel at ease, and develop target language vocabularies. In contrast to this, some sample students and teachers did not disclose the problems that might affect students' English learning ability. Again, audio-taped lesson results indicated that time devoted to English language was found to be insignificant compared to the time taken by the students' L1. The data obtained through audio-taped lessons also revealed that there were some problems of meaning difference between English and translated versions. Sentences and phrases often are mistranslated and confuse concepts while translating. Based on the findings, it is also essential to design an English course considering the relative importance of translating English into the students' first language. The study also suggested that translating English text books into the students' L1 would have a paramount importance on the students' ability to learn the target language. In addition, it is necessary to consider some impacts of an over-implementation of translation and the students' first language in a classroom.
\end{abstract}

Keywords: Major problems encountered, Translating Englishinto Wolaita Language, \& Primary schools DOI: $10.7176 / \mathrm{JEP} / 10-10-04$

Publication date: April $30^{\text {th }} 2019$

\section{Introduction}

It has been argued that anyone who has ever tried to translate between two different languages will understand the problems associated with language translation. These problems have been considered as a serious problem for translators for years. It has been argued that it is not easy to capture the same meaning when translating between two completely different languages. Language is a communication tool, and used in many different ways to express either the same idea or a completely different idea. It is again pointed out that problems arise when the translator attempts to translate word-for-word. This could be disastrous because the context in which the words are used is not taken into consideration. For example, in the English language, the word "market" can mean the 'stock market', or the' fish market'. Simply translating the word 'market' into another language without taking into account the context can change the original meaning completely. Moreover, quoting Howat (1984), cited in Kenenissa (2003) argued that the research evidence on the history of the development of English language teaching techniques tells us that the idea of using first language in the foreign or second language classroom was a respected view during the period of the Grammar Translation Method. Conversely, as Kenenissa (ibid) further stated, immediately following the WWI, a number of serious objections, the main problem being 
lack of everyday practical spoken language content, have been raised with regard to the grammar translation method. Since then, some perceptible number of linguists, such as Cole (1998); Cook (2001); and Prodromou, as cited in Kenenissa(ibid) argued that all popular English language teaching methods including the recently accepted communicative language teaching method have a tendency to discourage the use of L1 in the L2, or translating English into the students' indigenous language in the classrooms. This vision of learners' L1 avoidance has also been presented in most of the modern L2 teaching materials and syllabus. As a result, the English only approach has become an influential and often believed to be the hallmarks of good language teaching Atkinson (1987); (1993); Cook (2001). In relation to this argument, Cook (2001: 4) further asserted that the emphasis on the second language in the classroom rejected translation as a teaching technique.

Moreover, in the 1960s, the use of first language in the target language classroom was still seen as disagreeable by advocating the natural use of the target language for virtually all communications as a sure sign of a good modern language course. One argument for avoiding the first language is that children learning in their first language do not have a second language available. The other argument asserts that students should keep the foreign or second and first language separate in their minds rather than linking the two languages. Brown (2001) further indicated that many people who have undertaken foreign language learning at high schools or universities even in the past decades recall that teaching through translation was uninspiring, rather boring or even left learners with a sense of dissatisfaction when they move to the countries where the target language (English) is the only medium of communication. Edge(1986), on his part, also said that teaching through translation has perhaps not benefited as much as it might have done from the developments in the English classroom procedure that have made linguists see foreign language and translation unconnected. But some foreign language educators think translation as a critical means to guarantee students' comprehension and an important writing exercise while others totally outlaw or discourage the use of native language and translation in the classroom. However, there is an argument that for a language to play an important role as a medium of instruction there should be proficiency in communication between the teacher and the students. According to Girmaw (2007:3), effective communication is possible when appropriate language (medium of instruction) is used. The teachers are required to have a good command of both spoken and written language they are supposed to teach. They also need to have appropriate training on the language they are going to teach. Apart from problems emanating from lack of appropriate training of the teachers, lack of sufficient and appropriate instructional materials seem to pose serious problems when a target language is made to serve as a medium of instruction. As Malmakjear (1998:1), cited in Liao (2002:192) further stated, the issue of the use of translation in language teaching has been a controversial issue for a long time among language scholars, and fairly often, their views are not in favor of it.

Furthermore, as it was claimed by different linguists (Cook, 2001; Atkinson, 1987; Edge, 1986; and O'Malley (1990), some advocate the use of first language in the target language teaching on the grounds that it could increase students' comprehension while others totally refuse it. For instance, during the last quarter of the $19^{\text {th }} \mathrm{C}$, a revolution took place that affected much of the language teaching used in the $20^{\text {th }} \mathrm{C}$. The opposition was primarily against the stultifying methods of translation of texts and grammatical explanation, which were then popular. In its place, the pioneers of the new language teaching, such as Henry Sweet and Otto Jespersen, cited in Cook (2001:3) emphasized the spoken language and insisted on the importance of using the target language in the classroom.

Furthermore, from the turn of the twentieth century onwards, many theoretical works and practical methods in language teaching have assumed that a second language should be taught without the reference to the learners' first language. It has become a popular belief among teachers that translation of L1 gets in the way with the acquisition of L2.Unlike the above arguments, the Grammar translation Method views translation as essential for foreign language instruction and learning. However, this method has been criticized in foreign language teaching for decades Cole (1998); Cook (2001); and Atkinson (1987).Under the later developed Direct Method and Audio-Lingual Method, translation was banned and no longer included as a part of classroom activities. According to the communicative language teaching (CLT) approach, the target language is used during authentic, functional, communicative activities and students' native language has no particular role in the classroom. As many communicative language teachers argued, the best way for learners to achieve native like control of the target language is to think in that language rather than to translate or reprocess the target language into their mother tongue Kenenisa (2003). While many foreign language educators may have ignored the role of translation in language teaching, from the learners' perspective, translation is still widely used in their learning regardless of the above criticisms Naiman et al.(1978); Martiviano and Orquin (1982); O'Malley and Chamot (1990); Chamot (1987).

After the charter of transitional government of Ethiopia recognized the right of nationalities to use their languages as an instructional media, the idea of translating English into students' mother tongue become one of the common classroom activities though the current Ethiopian educational training policy did not officially endorse the issue of the use of students' first language in the English language classroom. Hino (1988), as cited in Liao (2002) also argued in his research work conducted on Japanese students that the use of translation in the 
target language classroom could impede the comprehension of the target language. As Hino further stated, unfortunately, Japanese students using first language in the target language classrooms tend to use translation while writing, listening, and speaking English or another foreign language. As a result, all skill areas suffered as students struggle to translate sentences word-by-word thus slowing down all language skills (both productive and receptive skills.

Moreover, when the Ethiopian People's Revolutionary Democratic Front (EPRDF) government replaced Derg in 1991, the new government recognized the rights of nationalities to speak, to write, and to develop their own languages. The current educational system, especially, in the choice of instructional medium, follows the logic of decentralized policy. As a result, over twenty nationality languages have been used as the language of learning in primary schools in different regions of Ethiopia McNab (1989:78). Teaching English as a foreign language starts in grade 3 or earlier by using transition to English-medium education in junior and secondary schools. However, the issue of the extent to which translation is used in the English language classroom is seldom raised by policy makers for second cycle primary schools. This shows that not much effort has been given on teachers' and students' first language preferences in a foreign language set up at primary schools. Thus, students who come from mother tongue dominated primary school classes fail to comprehend the teachers' presentation when they promote to high schools, where English language has been supposed to be dominant, if not totally, a medium of instruction. Students need each and every point of the contents to be translated; otherwise, they don't comprehend the teacher's presentation. Therefore, to satisfy the needs of all students, the teacher, intentionally or unintentionally, uses translation in the teaching of the target language. Therefore, I believe that this could be the result of translation dominated instruction in elementary schools where teachers use students' first language on the teaching of the target language.

In primary schools, the classroom instruction is dominated by translation of grammatical structures and there seems to be no adequate use of the target language, English. This in turn, reflects the above problems. But as Naiman et al. (1978) cited in Liao (2002:192) agree, good language learners refer back to their native language judiciously and make effective cross-lingual comparisons at different stages of language learning. But the writer of this paper believes that students' judicious L1 use theory could hardly be the case for Ethiopia, especially for rural primary school students. In contrast to Liao's (2000) argument, Kasmer (1999), whose work was cited in Liao (2000) conducted a study on the Taiwanese students stated that many teachers and linguists assume that translation does not belong to the classroom activities because it does not represent making full use of the target language. Added to this, Haltai (1989:288), cited in Cook (2001), pointed out that one of the important arguments that led translation to have bad name was the fear of interference errors. The argument is that translation fosters a sense of false equivalence between the two languages resulting in inter-language errors and having a very limited scope of objectives because speaking or any kind of spontaneous creative output is missing from the curriculum; students often fail at speaking or even writing in the target language.

\section{Objectives of the study}

The main aim of the study was to investigate the major problems encountered in translating English into Wolaita Language on the learning of English in primary schools, where there is a concern, as the writer of this paper believed, about the excessive use of translation and students' first language on the learning of the target language as a medium of instruction. Specifically, it sought to answer the following objectives:

1. What are the major problems encountered in translating English into Wolaita Language?

2. To what extent do teachers translate English into Wolaita language?

3. What is the position held by students about the use of translation in English classroom?

\section{Methodology}

According to Mertler and Charles (2005; Koul, L. (1993), the descriptive research design was utilized in this study. An audio-recording, document analysis, and FGD (focus group discussion) with students were administered as the main instruments used to gather data from the respondents. Moreover, the two selected primary schools, namely, Hobicha Borkoshe and Hobicha Bada primary schools, found in South Ethiopia, which are ranging in grade levels from $\mathrm{KG}$ to grade 8 , were selected as a focus of this study in order to make the sample size manageable. For selecting students, simple random sampling technique was employed. Concerning the sample size, top-three (first 3 ranking) students were selected to be interviewed from the two schools having 11 sections, 6 from Hobicha Borkoshe and 5 sections from Hobicha Bada primary school. In this way, 33 sample students were selected from the two schools to be interviewed. The predominant instrument employed for data collection from the sample teachers was the recording; as a result, three different English teachers' classroom lessons were audio-taped having one BA holder from Hobicha Borkoshe primary school and two diploma holders from Hobicha Bada primary school. Lessons were audio-taped so as to get rich data on the translation activities conducted in the classroom. Another major purpose of this instrument was to analyze the lessons presented and translated in connection to the major criticisms forwarded against the use of translation 
and students' L1 in English classroom. Even though the writer introduced teachers that observation and recordings were for the research purpose only, the exact objectives of this study were not disclosed. This was intended to prevent the problem of sensitizing teachers and students to show behavior different from the usual ones and by the help of this technique to get more natural data.

\section{Techniques of Data Analysis}

Audio-taped lessons were changed into written form and analyzed in a narrative way so as to see the translation problem on the students' learning as stated by different scholars. The non-verbal features, such as gestures were not taken into consideration for analysis because they are not measurable. The interview and document analysis results were also analyzed through qualitative way.

\section{Results and Discussions}

\subsection{Analysis of Audio-Taped Lessons}

The writer of this paper employed audio-taping as one of the data collection instruments in the grounds that it enabled him to capture scenes and interactions by means of tape-recorder because tape recorder was believed to be relevant in capturing the detailed information that might go unnoticed until scrutinized. To this end, lessons of three different English teachers were recorded, having one BA holder teacher from Hobichcha Borkoshe Primary School and two diploma teachers from Hobichcha Bada Primary School. The selection of these teachers was based on the information that the researcher had been informed from both schools because these teachers were more open than others to be tape recorded and to provide genuine data. These teachers were also considered as the role models for other teachers in that the school directors believed them honest to be tape recorded. Thus, the writer of this paper believes that the datum obtained through tape-recorder was unmodified, if not absolute. Then, the datum obtained in recording was converted into written form before being analyzed. Lessons recorded range in time from 40 to 45 minutes long. Having followed all these procedures, the researcher selected qualitative method to analyze tape-recorded lessons since qualitative method would show the possible problem of translation on the students' English language learning and would give the researcher an adequate opportunity to show the translation problem that has been discussed in the background of the study and the review of related works of this paper. The researcher further believed that qualitative method enabled him to give a comprehensive description and explanation of translation problems encountered by the students' learning in English classes.

The focus of audio-taped lessons mainly inclined to answer the research questions 1 and 2 on the grounds that these questions are more relevant to be investigated through audio-taped lessons than the research question 3 . In this regard, teacher-1 used translation and the students' mother tongue more frequently than teacher 2 and 3. Moreover, the second teacher's classroom discourse showed some possible problems could be encountered in language classes. His discourse more clarified the issues associated with the semantic relatedness in translation mentioned by scholars. In relation to this scenario, some few numbers of teachers also pointed out the same problem of "semantic relatedness" and "the problems in language translation". Moreover, some student respondents, though the majority advocates mother tongue use, revealed that using students' L1 may have some hampering influences on their learning. Therefore, what we can see is that over-implementation of the students' first language might have some negative consequences on English learning. One important issue that the writer of this study also likes to point out is that translating some strange words and sentences into the students' L1 should be allowed. For example, teacher-1 translated an English term "treasure" into Wolaytta language as "aqquwaa" This could be useful for learners to know the word, but over-implementation might have a humiliating factor on the students' English language learning and their English vocabulary. From the writer's understanding, translation and L1 use, if used minimally, seem not to be banned in English classroom because the data obtained through different tools indicated that translation has a positive effect on the students' learning. However, the study shows that its problem on language learning should not be seen as simple issue but care should be taken.

No matter how translation is seen as evil for English language learning, the second teacher's discourse indicated that the use of L1 seems to be relevant on teaching passive and active voice. But something that should also be disclosed here is that the second teacher should have discussed exclusively in English up to certain extent before introducing students' L1 so as to give opportunity for students to listen and practice English language; otherwise, it could be strange to say that students learn English. The researcher likes to prefer teacher 2 and 3's techniques of classroom discourse in that they employed much time for the target language usage than what teacher one did.

Notes on the Use of Some Codes and Symbols

Coding: the code 'T' represents 'teacher'; 'S' represents 'student'; 'Ss' represents 'students'; '...'( three dots) represent when the teacher and students were unsure of what they were saying, and/ or unnoticeable utterances or long utterances like 'um...' Non-verbal expressions like 'pointing to the students' ; 'nodding heads' ; and 
'frowning faces' were not considered because the researcher believed that they are somewhat difficult to figure out. Some capital letters and exclamation marks (!) were used to indicate when the teachers and students talked with very high tones of sound during the classroom interaction. Moreover, mechanics, such as comma, semicolon and other punctuation marks were added so as to make the recorded tape transcript readable and meaningful though the tape-recorder does not clearly show these features. Moreover, target language utterances were represented by "Rochwell" and students' L1 utterances were represented by "Verdana in bold" style in the text. Analysis' procedure followed the possible way that could show the problems of translation and the students' L1 in detail. The researcher selectively presented some moves of teachers and students (which the researcher believed relevant for the data) on the grounds that it would make feel the readers comfortable and it was also intended to reduce bulky text to a manageable size in such a way that it would show some translation defects on the students' English learning and would further make the presentation clear. Now, the researcher analyzed the script shortly as follows:

\section{Some Scripts from Teachers' Classroom Presentation}

T: Good afternoon class? (Tamaare naatoo Lo77o deetii?)

Ss: Good afternoon teacher? (Lo77o xoossaa wolqqan.)

As it has been pointed out in different sections of this paper, the use of translation has been criticized by different scholars depending on the evidence that they provided with. Here, as we can see from the teacher's greeting, the teacher translated the greeting 'good afternoon class?' into Wolayta language as "lo77o deetii tamaare naatoo?". But as Jiang (2002) stated, these expressions are connected in two different ways in that there is no time indication when "Good afternoon?" is translated into Wolayta language because 'afternoon' is not there in the translated version "lo77o deetii tamaare naatoo?" which can be translated back into English which reads "Are you ok?" that is different from the original greeting. Moreover, when the students' response "Good afternoon teacher" to the teacher's greeting translated into Wolaytta language reads as "Lo77o xoossaa wolqqan". But when it is translated back into English, it reads, "Good in the power of God" which seems completely different from former greeting. Therefore, the study shows that translation and the students' L1 use in the English class would affect the pupils' ability of expressing themselves during greeting. In relation to this problem, one of the students' focus group discussion results revealed that the mismatch of the meaning of two languages is one of the problems being encountered in English learning processes. In connection to this problem, some scholars argued that it is not easy to capture the same meaning when translating between two completely different languages. Therefore, this evidence clearly indicates that Wolayta language (which is mostly tonic) could not directly be translated into an English language. What the writer of this paper likes to suggest here is that there would perhaps be better English language learning opportunities which might have come if the teacher exposes students to the variety of greeting styles in such a way that students would get ample chances to use English language. Therefore, the writer believes in Cook's (2002) argument in that translation fosters a sense of false equivalence between the two languages resulting in the inter-language errors.

T: Thank you. Who can remember the previous lesson? Yes? No one? "Kase galla tamaaridoogaa hassayiyay baawee?" Heya...?

As Titford (1983) stated, a word-for-word translation is believed to be a faulty translation of the target language into the students' L1 which is presented to the students as a means to provide insights about the previous lesson ranging in length from sentences to a single word. What the technique may do is to expose the wrongness of assuming that a sequence of items ' $a+b+c$ ' in English can be adequately translated into first language with a similar sequence of ' $a+b+c$ '. This example clarifies how the problem of translation prevails. For example, an English expression 'Who can remember the previous lesson? had been translated into Wolayta language as, "Kasse galla tamaaridoogaa hassayiyay baawee?" But the translated expression does not show the question of ability to remember the previous lesson; rather it shows as if it was 'is there no one to remember the previous lesson?' Moreover, the word "baawee $/ \mathbf{b}^{a}$ : we: /?" in Wolayta language is not there in English expression. Therefore, from data it can be believed that an argument put forward by Titford (1993) above seems to be true for the problem of translating English into Wolayta language. However, the students' opinion obtained through focus group discussion indicated that students see translation and the use of their first language a resource for learning English language. The researcher's experiences as a student of one of the schools under investigation shows the same state of affairs in students use to shout against the teacher whoever uses English exclusively in the classroom. In this regard, Duff's (1989) idea concerning the importance of the students' L1 seems to be relevant to be recommended. He stated that translation and the students' L1 helps to rouse discussion and assumption; to develop clarity and flexibility of students' thinking and to help language teachers increase their own and their students' awareness of an inevitable interaction between English and L1 that occurs during language learning and teaching.

T: Ok, this is all about the previous lesson. Today we are going to see lesson five, Birds, the National Treasure of Ethiopia. "Treasure giyoogee woygiyoogee?" hi? Eriyay baawee? Woygiyoogee? Yes? Aqquwaa giyoogaa. Xaafite birshshettaa. Ha co77u giidi uttida naati woy xaafitte woy kifliyaappe kiyitte. Hello...! 
Ok, now open to page 92 . Who can read the passage? No one? Nabbabanna danddayiyay baawee? Oonee nabbabiyay? Naatoo intte ha xekkan nibaabiyaa danddayana xaykko iittattenne. Ishi maccanaatuppe oonee nabbabanay? Ok, Almaz, continue.

As far as the researcher understands, English teacher even in the past couple of decades use the students' L1 and translation dominantly as presented above. In this regard, the researcher believes that pupils seem to have developed the habit of hearing in English and saying things in Wolayta language. This bad habit, as stated in Cook (2001), is likely to increase in magnitude because some of the teachers insist on the use of the students' L1 and translation as a matter of course, even where there is a possibility to try their move in English. For example, "treasure..." which could be strange for students looks good to be translated in to Wolayta language as "aqquwaa". But the other uses of mother tongue discourses seem to close the way through which students could practice in using the target language. The expression "hii?" is usually used by many Wolayta language speakers to show something is not clear for some one. Most Wolaytta students couldn't say 'sorry' or 'excuse me' when they need some extra explanation. Moreover, the teacher translated an interrogatory statement "who can read the passage?" into Wolayta language as "nabbabanna danddayiyay baawee?; oonee nabbabanay?" The above discourse indicated that the pupils are very unlikely to learn English and other subjects in English with this kind of use of instructional medium and neither can the teacher teach efficiently. Because in the above translated sentence, the data couldn't show the idea that expresses the passage to be read by students, but it tells that "nabbabanna danddayiy baawee?", which can be translated back into English reads 'no one can read?' Hence, the researcher believes that the subject of the sentence; the verb and an object can be unnoticeable for the learners when it is translated into Wolayta language, which in turn can affect the students' English language learning. Therefore, the researcher believes that it is not difficult to see the effect of using translation or vernacular on the students' foreign language learning.

T: Now, Almaz stop. Who can read the next paragraph? "Kalliyaa menttuwaa oonee nabbabanay?"

The teacher's version in the above sentences shows the problem of introducing dissimilar mother tongue versions for an English language. Here, the teacher used "menttuwaa" for an English word "paragraph". But as far as the researcher is the speaker of Wolayta language, "mentuwaa" has a multi-faceted meaning depending on the different contexts like? "menttuwaa"-'type or kind'; 'line', 'blood relation between persons', etc. Therefore, the researcher believed that this kind of translation usage may unintentionally be amalgamated with a sense of false equivalence between mother tongue and English resulting in an inter-language error as Cook (2002) argued. But what needs to be disclosed here is that, according to the teacher's use, it has some quality of adding teacher-student rapport, which has been stated by some scholars in arguments that favor L1 use in an English classroom. However, its disadvantage seems to outweigh the advantage.

T: "Thank you very much for your reading. Now, you will do the following task individually based on the passage. Read the passage silently. Immettida nibbaabiyaa co77u giidi nabbabitte. Then, answer the gap questions by using the context clues and recall skills. Recall skill giyoogee woygiyoogee? Yes...? Please. Woygiyoogee...? Hassayaa giyoogaa. Ok, now read and answer questions individually. 5 minutes. Hurry up!"

It seems more relevant in the first translation than the second one in that the teacher provided English version first followed by its translation as follows:

\section{English version Translated}

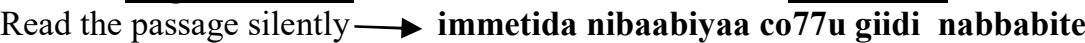

As it was stated by Bolliger and Sears (1980), this technique could be taken, of course, as one of the strategies in which learners can benefit from and learn a foreign language and communicate it effectively. This is believed to be code-switching between the two different languages in such a way that language teachers and students introduce a word or phrase that does not exist in the learners' second language. But in the second case, teacher's translation would have some possible effects on the students' learning because the phrase 'recall skill' has been translated as a single word as "hassayaa", which can also be translated back into English reads 'remember'. But, as it can be seen from the phrase itself (recall skill); it is related with ability to remember. However, translated version does not show this fact. Thus, unwise way of using translation and the students' first language could have a paramount effect on the students' English language learning. But what the researcher likes to suggest here is that it is better if teachers use English followed by Wolaytta language. But the sample teachers use translation and the students' L1 to present the whole lessons. The writer of this paper further believes that it is more relevant if the students' L1 is used to clarify more difficult concepts than using each and every turn. In contrast, asking question,; commenting on the student answers; giving instructions; explaining words; managing student behavior; nominating student behavior and proving students should be carried out through the use of English language in such a way that students could get ample opportunity to learn and practice the English language.

T: Ne sunttay oonee? What is your name giyoogee qassi direct question geettees. Now it is time to stop. Sinttaa 112 de7iyaagaa soo biidi nabbabite. Take it as homework. 
As it can also be argued from the above language usage, the students' vernacular "ne+sunttay+oonee?" does not fulfill the $\mathrm{S}+\mathrm{V}+\mathrm{O}$ pattern of the target language usage. But, it gives the exact meaning for an English version "what is your name?" No matter what it transfers the meaning of an English discourse; "what is your name?" hardly seems to show the students the target language structures. Moreover, the teacher's expression, such as "giyoogee", "qassi", "geettees" does not exist in an English language pattern used above by the teacher. For example, what is your name? This question can be interpreted by Wolayta language speakers from right to left. Hence, the researcher believes that language patterns used in English can hardly be translated into Wolayta language, which in turn may affect English learning procedure of students. The sentence pattern that can be seen from, "Rahel wanted to know if my name was Mimmi" reads "Rahela ta sunttay Miimokkonne eranawu koyaasu" as it was translated by the teacher. But the researcher believes that language patterns, usage and message comprehended could in no way be similar because the sentence elements- 'to', 'if', and the past marker 'was' are not present when it is translated into Wolayta language. Taking all these drawbacks into consideration, the researcher clearly likes to argue that language structures in both languages (English vs. Wolayttato) are unconnected. Furthermore, when the teacher was providing homework for students, he used an English version "take page 112 as a home work." and translated into Wolayttato as "sinttaa 112 de7iyaagaa soo biidi nababite." Now, the translated version contains more word pattern than an original English version. For example, "de7iyaagaa", "soo", "biidi" and "nabbabite" are the language patterns that do not exist in English version. From these problems, the writer of this paper likes to generalize that English language seems more relevant to be taught without reference to the learners' first language.

T: Those students who did not bring your text book...hands. Raise your hands. one, two, three, four, and five.

Why you didn't bring your text book? You...? Yes?

\section{S: Doggaas}

T: Kan77iyaa meennan doggada ya eray? Now maxaafaa ehibeenna naati wodalut ga hidu.

As can be observed from the above three turns, the student answered the teacher's question using Wolayta language. In response to the students' reply, the teacher also used students' L1 in advance. From data, we can infer that there was a little chance of using English from both students and the teacher. Thus, there is a high probability of making students seem dependent on L1 and preventing them from understanding distinctions in English. Hence, the teacher's and students' L1 use in the above sentences has, as the researcher believes, no valuable contribution on the classroom English language learning pedagogy. Therefore, the researcher provides the following reasons to make English and students' L1 separate from each other: the fact that the first language does nothing to advance the learning of the target language as it is clearly stated in the above statement.

By and large, as it has been stated in the three teachers' moves, the classroom interaction was dominated by the teacher. The data do not show when students take an optimum part in the classroom, which in turn reflects the issues criticized in the Grammar Translation Method (GTM).

\subsection{Results of Focus Group Discussion (FGD) with Students}

The writer of this paper held discussions with a group of students in the two selected schools. No matter how each of the groups held discussions with the researcher on different days, what all of them said about the use of translation in the target language classroom were almost the same. The first question posed for discussion was the type of language that grade 8 English teachers use while teaching English. Almost all of them, except little unnoticeable number of students, revealed that their target language teacher uses Wolayta language as a medium of instruction. And the writer of this paper added a follow up question for the target group students. "Which language do you prefer most and why?" Students responded that they need both English and Wolayta language together, otherwise, they added, it could be difficult for them to get what the teacher is saying. Another member of the group said that English teachers, most of the time, use English language, but they need English language to be translated to their L1. They also verified that they ask their English teacher to translate some difficult words and sentences for them. Another argument put forward by the discussion groups is that it could be bad if the teacher exclusively uses their mother tongue on the grounds that they could not get any possible method to train English language. Students further revealed that they have a doubt to say that the translation usage of all teachers is clear. Moreover, in connection to the translation and the related problem stated that alien concepts which cannot be easily translated into a particular language and dialect differences and lack of standard usage for some words are among the key problems which affect the quality of students' language learning. For another question, the target groups provided the same response in that they ask their English teacher to translate English language into Wolayta language until it becomes clear for them. From this evidence, we can also deduce that the students overtly need English language to be translated into their mother tongue. Students gave the same response to the seventh question as they did in the questionnaire session in that the possible negative effect, if used entirely, of translation is that it affects the students' ability of developing the target language skills. This argument could be substantiated with the argument in that a number of serious objections, the main problem being lack of everyday realistic spoken English language content, have been raised with regard to the grammar 
translation method (Harmer, 1991).

Generally, discussion groups further responded that teachers use translation and the students' L1 when students become silent when they were asked about the day's lesson. But, as it was pointed out in the interview with English teachers, language teachers use translation, as well as the students' first language because of lack of English speaking competence. They boldly pointed out that the setting where they live; the community itself; and the general socio-economic problems they face day-to-day adversely affect the target language teachers' ability to teach their students and to use the language itself as well. Some of the interviewees (teachers) again said that even they are facing some challenges to compete with the existing situations in universities when they join higher education program. Finally, teachers asked the researcher to show the direction through which they can develop English language speaking ability. The majority of the student interviewees argued that they hate the teachers who usually use only English and they consider such teachers as boasting. Another half of the students also asserted that teachers' translation and their mother tongue usage is their own criterion to differentiate a teacher as good and bad, i.e. if the teacher does not use their first language they automatically hate him. On the other hand, they also like teachers who use their mother tongue. The researcher's background experience also shows the same cases with what the students argued concerning the use of translation and their mother tongue in English classrooms. Therefore, it looks possible to generalize that students reported through focus group discussion that they need translation and their mother tongue on the learning of English language.

\subsection{Results from document analysis}

The main objective in this study reads "What are the major problems encountered in translating English into Wolaita Language?" To answer this objective, some translated documents were reviewed and interpreted. In this regard, the researcher found supporting information for the problem of translation, i.e. the translation problems caused confusion at Obama-Hu news conference held in the White-House (posted by Erica Werner (CP).

Translation mix-ups led to some confusion at White-House news conference with President Barrack Obama and Chinese president Hu Jintao. Obama initially thought his responses were being translated simultaneously into Chinese for Hu. But they were not and the Chinese language translator had to get on a lengthy translation after Obama's response to the first question he was asked about human rights. "I apologize, I thought we had simultaneous translation there," Obama said after he realized what had happened... later in the news conference, Hu Jintao willingly discussed the China's human rights issues, explaining that he had not heard the question the first time around because of the technical translation and interpretation problem.

This evidence indicates that there would be no exact meaning correspondence between two languages so as to transmit the direct messages of the source (target) language into the first language. In line with the translation problem created in White House, what the writer of this paper would also like to point out here is that the difference of dialect, culture, and language variation could be the barrier even for the language learners in the school setting, most shy students would not ask for further clarification as what had happened in white house. This further implies that translation activity even in English language teaching could have a paramount effect on the students' learning on the grounds that translation could not render similar meanings of the original language into the listeners' vernacular language, which in turn could create the communication barrier between speakers and audiences. Therefore, the language teachers still seem required to do a translation job well. To cite another example here, the researcher found supplementary evidence for the problem of translation from the reporter news paper under the title "Lost in translation", posted on Saturday April 09, 2011, p.14.

"A friend of mine was telling me about a trip she took to a monastery outside Addis, where she came across a sign that reads "please stretch your hands". After a few minutes of confusion, she read an Amharic version which said " "(please deep in your pocket"), figurative ways of saying "please donate to the church”. Leyu (April 09, 2011, p.14; Reporter news)

Thus, what we can also conclude from this datum is that translating one language into the other one could in no means transfer the same meanings for different readers and listeners. Even the writer of this paper himself believes that the above two versions, "Please stretch your hands" and "please donate to the church" are different in message. Therefore, the listeners have a rare chance to comprehend the intended message so that it is hardly possible to get some money for the church from the people. Likewise, the researcher believes that translating English into Wolayta language might have its own influence, as it is also presented earlier, on the primary school students' learning of English.

To see the gap of translation further, let's see the following:

English version: Did the university entrance examinations help you to speak English?

Mother tongue version (Wolaitttato): Yunburshiyaa geliyo paaccee nena

Inglizzettuwaa eranawu maddidee?)

The students may face difficulties to identify the meaning of each translated words. For example, the above English version has 10 words, but mother tongue version (Wolaitttato) contains 7 words, so how could students 
identify the simple past marker "did", preposition "to" or the second person plural marker "you"? However, as it can be understood from many international schools and colleges, to develop English language, students are trained in English only approach, especially when they are going to be certified with TOEFL at the British council in Addis Ababa, capital of Ethiopia.

To cite more, an English phrase "Motivation of English Technical College Students" has been translated into the students' indigenous language (Wolaita language) as "Inglizzetto koolleejjiyaan luxxiyaa naatu qaattaa", but there is no mother tongue version for the term "college". Moreover, some words, such as "motivation", "of", and "students", etc in the above English version lack direct meaning. Due to these reasons, it has been argued that anyone who has ever tried to translate between two different languages will understand the problems associated with language translation. These problems have been considered as a serious problem for translators for years. It has been stated that it is not easy to capture the same meaning when translating between two completely different languages. Language is a communication tool, as further said. It can also be used in many different ways to express either the same idea or a completely different idea.

\section{Conclusions}

Three research questions were addressed in this study, and the principal findings suggested that most participants, especially learners approved that translation plays a positive role in their English learning experiences, but participants also had conflicting arguments about translation, resulting from their different understandings of both positive and negative effects of using translation. On the whole, translation seems to play an important facilitative role in primary schools students' English language learning processes. According to students' shared opinions about using translation in learning English, generally they expressed the inevitability of translation use at their current stage of learning, and see translation as a positive learning resource for them to comprehend and learn better English. However, some teachers also showed a somewhat contradictory feeling towards translation. On the one hand, they apparently believed that without translation, it is unlikely to make students learn the language. Teachers were also concerned that translation might 1) close the way through which students could develop English learning opportunity 2) inhibit students' thinking in English 3) make learners assume that there is a one-to-one correspondence of meaning between English and Wolayttato, and thus become a 'bottle neck' on students' advancement in English learning. As a result, some respondents believed that they should gradually refrain from using translation as a learning tool of English. Another major finding of this work indicated that teachers may not need to ban the use of translation on English learning altogether and they should be more aware of the occasions when translation can be more beneficial to the students' English learning. This had also been reflected on Students' focused discussion results in that students expressed that they need translation whenever it is essential. Both teachers and students agreed that English teachers should use translation sometimes. The study further revealed that students believe in the various pedagogic use of translation and their mother tongue in that translation and the use of L1 help them to know difficult concepts; understand new vocabulary items; make learners feel at ease , comfortable and less stressed. An overwhelming number of participants, moreover, did not advocate the idea of the total rejection of mother tongue and translation usage in English classroom. This, in turn implies that an exclusive English-use theory recommended by Ellis (1985) in English learning could hamper the possible students' English learning ability. The majority of the respondents argued the importance of translation. However, the data obtained through an audio-taped lessons and document analysis exhibited that there was a mismatch of meaning between translated and English expressions due to the influence of lack of appropriate language training service for English teachers and teachers' lack of exposure to the target language speaking community put forward for inefficiency.

Even though some unnoticeable number of students and teachers did not like the use of translation and students' L1 in the classroom, the responses gained from all students revealed that students have a great tendency to learn English well when some difficult vocabularies, phrases and sentences are translated into Wolaytta language. But these respondents also disclosed the possible problems that could be encountered on English learning if the teachers exclusively used Wolaytta language as a medium of instruction. This fact seems to outlaw Ellis's (1985) view of exclusive-English using theory on English language teaching and learning

Thus, even if translation and mother tongue use have been criticized by majority of scholars and some participants, it is found to be useful because it prepares for or consolidates activities by relating L2 to L1. It builds on what learners already know about the usage of their L1 to build up their knowledge of how to use the English language. From the arguments that have been put on in this study, it is not difficult to see the effects of the use of students' mother tongue and translation on foreign language learning. However, I cannot generalize from this limited data, such weaknesses are very likely to be seen in other similar schools, and therefore, it is reasonable to put some suggestions. If English is to be used as a dominant medium of instruction in schools, there should be restructuring programmes so as to strengthen the position of teaching and learning the language in schools. It has also clearly been stated in this paper that teachers take too much time explaining structures (doing grammar analysis) to the students who know very limited number of English words. A part of these times 
could better be spent in practicing language skills in English.

\section{References}

Atkinson, D. (1987). The Mother Tongue in the Classroom: A Neglected Resource?: ELT Journal. Vol. 41 No. 4: PP.241-47.

(1993).TeachingMonolingualClasses.UsingL1 intheClassroom.Harlow: Longman Group Ltd.

Bolinger, D.L., and Sears, D.A. (1980). Aspects of Language ( ${ }^{\text {rd }}$ ed.). NewYork: Harcourt Brace Lovanovich.

Brown, H.D. (2001). Teaching by Principles: An Interactive Approach to Language Pedagogy (2 ${ }^{\text {nd }}$ Ed.). White plains, New York: Longman.Candlin.

Chamot, A.U. and O'Malley (1987). The Learning Strategies of ESL Students, in A.L. Weden an and J.Rubin(eds.). Learner Strategies in Language Learning. Englewood Cliffs: Prentice Hall,Inc.

Cole,S. (1998). The Use of L1 in Communicative English Classrooms. The language Teachers' Journal, on-line internet. Available: http:www.JALT Publications.org/tlt/files/98/dec/cole.html

Cook, V. (2001). Second Language Learning and Language Teaching. New York: Oxford University Press, Inc.

Corson, D. (1990). Language Policy Across the Curriculum. Cleve den: Multilingual Matters Ltd.

Duff, A. (1989). Translation: Resource Books for Teachers. Oxford: OUP.

Edge, J. (1986). Acquiring Disappears in Adultery: Interaction in Translation Class. ELT Journal, 40/2,121-124.

Ellis, R. (1985).Understanding Second Language Acquisition. Oxford : OUP.

Farrant, J. (1997). Principles and Practices in Education (New ed.). Singapore: Longman Singapore Publisher PVTCTD

Ghermai, A. (1998). "The Primary Curriculum and Language Issues in Ethiopia." In Amare Asegdom (edit.). IER Flambeau, Vol.5, No.2, Addis Ababa University.

Girmaw Allene (2007). Assessment of Teachers' Performance in Teaching Using Awngi as a Medium of Instruction in the First Cycle of Primary School in Awi Administrative Zone. Addis Ababa University. (Unpublished).

Gray, A.(1950). Foundation of Language. New York: Macmillan.

Kenennisa Berisa (2003). Using L1 in the EFL classroom: The case of language with Particular reference to Adama Teachers' College. MA thesis (Unpublished).

Koul, L. (1993). Methodology of Educational Research (3 ${ }^{\text {rd Revised }}$ Ed.). New Delhi:Vishal Printers.

Liao,p.s.(2002). Taiwanese Students' Belief about Translation and Their Use of Translation as a strategy to learn English (PhD thesis) .Austin, USA: The University of Texas in Austin.

McNabb, C.(1989). Language policy and Language Practice: Implementation Dilemmas in Ethiopian Education. Stockholm : Stockholm University.

Malmkjar, K. (1998). (Ed.). Translation and language teaching: Manchester, UK: St.Jerome Publishing.

Marviano,M.D. and V.Orquin (1982). Identifying your students' Strategies for learning English as a foreign language. Modern English Teacher, 9/4, 38-41.

Mertler, C.A. and Charles, C.M. (2005). Introduction to Educational Research (5 ${ }^{\text {th }}$ Ed.). New York: Pearson Education, Inc.

Naiman , N.M. ;Froehlich, H.H. Stern, and A. Todesco (1978). The Good Language Learner. Toronto: Ontario Institute for Studies in Education.

O’Malley, J.M. (1990).Learning Strategies in second language .Cambridge: CUP.

Osler, A. (1994). Development Education: Global Perspectives in Curriculum. Britain: Redwood Books, Trobridge Wiltsire.

Seliger,H.W.and Shohamy,E.(1989). Second Language Research Methods. Oxford: UP.

World Educational Encyclopedia (1998), Vol.II. New York: George Thomas Kurian Publishing Company.

\section{Author Profile}

Mesfin Mekuria Dangore received a B.Ed. degree in English language and literature from Dire Dawa University, East Ethiopia in 2009 and MA Degree in TEFL (Teaching English as a Foreign Language) from Addis Ababa University, Ethiopia in 2011. Higher Diploma Program (HDP) Certificate from Wachemo University, South Ethiopia on July 02, 2014. 